\title{
BASES BIOÉTICAS PARA LA TOMA \\ DE DECISIONES EN LA PRÁCTICA MÉDICA, INVESTIGACIÓN EN HUMANOS Y TRANSPLANTES
}

Casas Martínez, Ma. de la Luz

Trillas, 2008

Amanda E. González Bolaños*

amandaglezb@yahoo.com.mx

Actualmente, la filosofía de la medicina se enfrenta a complejas propuestas de la tecnociencia y a las presiones socioeconómicas, por lo que es de vital importancia hacer una revisión concienzuda sobre los fundamentos de la Bioética ante estos elementos.

El núcleo de actuación en la relación médico-paciente es la corporeidad, y los avances tecnológicos, científicos, sociales y legislativos inciden necesariamente sobre el estudio del cuerpo humano, considerándose al cuerpo como sujeto y objeto de estudio.

Las funciones de la medicina están orientadas a prevenir, conservar y restablecer la salud, evitar complicaciones y secuelas, y en especial, evitar la muerte están abocados a procurar el bienestar y conservar la vida rigiéndose por principios éticos que salvaguardan la integridad del ser humano en su más amplia expresión. Los fines de la medicina tienen una característica esencial: la atención ética del ser humano en estado de enfermedad.

Los objetivos tradicionales del acto médico deben considerar nuevas interrogantes:

-- Salvar y prolongar la vida, pero ¿vale la pena prolongar la vida sin esperanza?

2.- Promoción y conservación de la salud, pero ¿Es justo que sólo accedan a la atención médica los que cuentan con medios económicos?

3.- Alivio del dolor y displacer, pero ¿es válido en un caso así la eutanasia y el suicidio asistido?

4.- Alivio del sufrimiento, pero ¿se justifica el uso de psicofármacos en personas que buscan solventar las preocupaciones de la vida cotidiana, así como los problemas existenciales, psicológicos, espirituales y de sentido de vida?

El médico y su criterio ético, ciencia y conciencia, eran hasta hace poco suficientes en el ejercicio de esta ciencia-arte, por lo que es necesaria una nueva visión de la corporeidad humana y un nuevo modelo de atención médica 
basada en la idea de autonomía del paciente.

El sustrato del acto médico es el cuerpo humano, es la superficie visible (corporeidad) de acción del personal de salud. El antecedente mecanicista de Descartes ha evolucionado hacia una visión matemática, la cuál es la realidad observada por el médico científico; sin embargo la ampliación de las capacidades humanas mediante el uso de la tecnología, especialmente de la "inteligencia artificial" y en el campo de la ingeniería genética hacen que la visión de corporeidad limitada sólo al aspecto tangible de la realidad sea insuficiente para fundamentar las nuevas consideraciones éticas que el avance tecnológico en el campo de la Medicina ha imperado en los últimos años.

Desde el modelo matemático, la corporeidad se reduce a materia y ésta presentada de la manera mas abstracta posible, alejándola de la verdadera realidad humana, en que el ser humano se proyecta a la vivencia, convivencia y la trascendencia.

Actualmente, en la corporeidad descansan las raíces de la individualidad, de la intimidad y del sentido moral, datos que se proyectan en la inviolabilidad de la personalidad; la corporeidad es el mundo donde la privacidad, la integridad, el respeto y la confidencialidad se hacen patentes.

El valor de la corporeidad es actual en el debate de la Bioética, ya que es el fondo de las discusiones sobre el acto médico, como la psicocirugía, los cuidados terminales, la eutanasia, la experimentación y el uso del cuerpo y sus partes a través de transplantes y la genética.

Cuando se considera el estudio del hombre apartado de las ciencias humanistas, se actúa de forma reduccionista y biologista, pues se considera al Homo sapiens con una diferencia muy pequeña de los demás antropoides.

La relación médico paciente debe sustentarse en la idea filantrópica de la medicina, para la cual, lo principal es conocer quien es el paciente, construyendo una medicina más integral y humanística, basada sobre una patología formalmente personal que repercute en el reconocimiento de la importancia de la subjetividad, haciendo énfasis de la importancia de los sentimientos en la decisión personal, concordando con la idea del Homoinfirmus. 
La Medicina clínica actual debe reintroducir al sujeto epistemológico, al paciente integral, autoconsciente e interprete de sí mismo, dando un modelo explicativo de la enfermedad como problema humano, como modelo de comprensión y participación en el modelo biopsicosocial, considerando las interacciones de la persona integrales, ecologistas, económicas y políticas [Esta línea no queda clara porque o se aclara a qué está atribuido el concepto 'integrales' ].

La posibilidad de obtener a través de la transplantología y la biogenética al "hombre perfecto", un ser humano producto de la libertad humana, representada por la ciencia y la tecnología, un ser producto del "deseo humano", cuestiona sobre la soberbia de la ciencia moderna que intenta la "creación tecnológica" de un ser humano libre de procesos patológicos.

Además, ante las posibilidades reales de que partes de otros cuerpos convivan en un solo sujeto, de que se combinen partes genómicas, como es el caso de los transplantes, surge un nuevo significado de la individualidad y de una nueva cultura y dimensión intersubjetiva del cuerpo.

Debe replantearse si el hombre tiene derecho a manipular lo natural sin respetar el orden necesario (en caso de que existiera en la ley natural un telos -razón) o el supuesto orden azaroso surgido de las posibilidades evolutivas (en caso de que la ley natural sea el resultado de la replica de leyes fisicoquímicas de manera mecánica y al azar).

En el "Human Genom Proyect" se vislumbra tanto un beneficio insospechado como una ilimitada catástrofe al poder el hombre incidir sobre la fuente misma de la vida, sobre las leyes antes inmutables, sobre el ritmo evolutivo de lo creado, sobre la posibilidad real de transformar seres vivos naturales en antinaturales y de considerar con el tiempo que esa consideración de antinatural, es natural. Es la idea misma de la especie humana lo que está en riesgo. 